\title{
THE ROLE OF A POSITIVE TRIGGER EVENT IN ACTIONING AUTHENTIC LEADERSHIP DEVELOPMENT
}

\author{
S PUENTE \\ F CROUS \\ A VENTER \\ anitav@uj.ac.za \\ Department of Human Resource Management \\ University of Johannesburg
}

\begin{abstract}
Authenticity can best be understood in context, and context implies action (Payne, 1996). For the purpose of this study, leadership in general, and authentic leadership in particular, were explored in terms of the actions of former mayor of New York City, Rudolph Giuliani, who displayed authentic leadership in action during the tragic aftermath of the World Trade Centre attacks. Authentic leadership development tends to be triggered by a negative event (as in the case of 9/11 for Giuliani, for example). Since there is limited knowledge of how a positive event may trigger authentic leadership development, the aim of this study was to explore the potential of Appreciative Inquiry (AI) an affirmative mode of action research - as a positive trigger event for authentic leadership development. The results indicated that this positive approach to change could indeed be implemented for this purpose.
\end{abstract}

Key words

Authentic leadership, authentic leadership development, positive trigger events, action research, appreciative inquiry

". . . to be authentic is literally to be your own author, to discover your native energies and find your own way of acting upon them. Not existing simply to live up to an image posited by the culture or some other authority." (Bennis, 1993, p. 4).

\begin{abstract}
Authenticity in action
On 11 September 2001, the world watched as Rudolph Giuliani, the mayor of New York City, led the city and the American nation in the aftermath of the tragic World Trade Centre attacks. 9/11 had a significant impact on the world both economically, socially, emotionally, and psychologically.
\end{abstract}

Giuliani was hailed by some in the press as an exceptional leader in the face of this tragic event. The question is: what made this man so exceptional, and how did he show up in the world, during such a chaotic, dark and negative experience? Leadership theories advocate an array of possibilities. According to the trait theories (Covey, 2005; Avery, 2004; Nelson \& Quick, 2004; Sharma, 1998), Giuliani had various physical attributes and personality characteristics in his favour, such as age, adaptability, optimism and emotional control. On the other hand, during his career as a Federal prosecutor, one could argue that Giuliani devoted much of his time in developing his leadership abilities such as speech fluency, social skills and insight, as proposed by the behavioural theories of leadership (Covey, 2005; Nelson \& Quick, 2004; Avery, 2004). As a leader he was strong and direct, yet still remained responsive, interactive and collaborative in his actions with his administration (Nelson \& Quick, 2004; Shipka, 1997).

The contingent leadership theories advocate that situational favourableness contributed to Giuliani's effective leadership during 9/11, namely that there was a structured task for him and his administration, he had a strong position of power as mayor, and he maintained excellent relationships with members of his team as well as the people at large (Nelson \& Quick, 2004). However, the complexity of Giuliani's leadership effectiveness cannot be limited to these leadership theories.

Giuliani understood how to convert his vision and desires for the people of New York City into a reality, and he inspired his administration and close work colleagues to perform 'above and beyond the call of duty.' "The stunning number of deaths after 9/11 meant I could not attend every funeral; and this was unacceptable. I decided to establish a triage to make sure that a city representative attended every funeral, and I told everyone at the meeting that I expected them not just to attend, but to make their presence felt, speaking to and comforting the victim's survivors" (Giuliani, 2002, p. 262).

This kind of action resonates with leadership often referred to as transformational. Giuliani had an innate ability and talent to influence his environment and he inspired those around him to pursue the greater vision, and thus the people of New York warmed to his charismatic nature at the most crucial point in his career - during the fear and uncertainty of 9/11 (Nelson \& Quick, 2004; Sharma, 1998; McCauley, Moxley \& Van Velsor, 1998).

Giuliani's great leadership capabilities tend to be a melange of the above mentioned leadership views. However, a common thread underlying all of these theories is that no matter what the situation, Giuliani acted consistently with his beliefs and core values - i.e. he was authentic.

In his autobiography, Leadership, Giuliani describes how the events of September 11 affected him more deeply than anything he had ever experienced, but he did not feel that he became a different person on that day. The "pre-September 11 Rudy" and "post-September 11 Rudy" was the same person (Giuliani, 2002, p. $x$ ). During this time, Giuliani made a decision that he would implement the same leadership he had used throughout two terms as mayor of New York and five years as a U.S. Attorney. In other words, Giuliani made a conscious decision that he would remain authentic to his core, fundamental values, and allow this authenticity to guide his actions and decisions in the weeks ahead of him.

Giuliani depicts the type of positive leadership needed presently, where the environment is dramatically changing, the rules are changing, and where leaders want to live out a natural link between their espoused values, actions and behaviours (Luthans \& Avolio, 2003).

Authenticity is not a static state located in a moment of time (Quinn, 2004; Lewin \& Regine, 1999; Quinn, 1998), but flows from being truthful and open in a relationship. Authenticity can be illustrated through descriptive words such as "genuine, reliable, trustworthy, real and veritable" (Luthans \& Avolio, 2003, p. 242). According to Quinn (2004), authentic leaders are other focused, externally open, internally directed and purpose centred. Giuliani displayed these characteristics and may therefore be defined as an authentic leader: As a leader, Giuliani pursued purpose in the face of ambiguity and the unknown 
(purpose centred), and his values and behaviours were congruent and aligned (internally directed). Giuliani had the ability to nurture a climate of trust and naturally put the common good and welfare of others first, thus increasing his authenticity and transparency. Giuliani also had the facility to tune into people's feelings - his own and others - and guide them in the right direction (other focused). Lastly, Giuliani was confident in journeying forward in an uncertain and changing world (externally open).

Giuliani took the risk of being authentic during a very chaotic and sombre time, knowing that being authentic would connect him to those around him, and help him and others to truly be present in a trying moment. Being authentically connected to his administration, rather than being disconnected, was his unique way of approaching the daunting task of calming not only New York City, but the global village at large. Giuliani, in addition to fulfilling great leadership resilience and action, acted upon his personal authenticity. There are four relational practices, according to Lewin and Regine (1999), which were enacted by the then mayor of New York - he expressed his authentic self as a leader, he acknowledged others, he was accountable, and lastly, he was attentive to the needs of the city and the people within it. This is what made Giuliani so authentic. His conversations and interactions with people generated positive connections and rewarding relationships. His emphasis on connecting with people nurtured trust, affiliations and constructive conversations.

Just hours after the attack on the World Trade Centre, Giuliani had a meeting with his administration, where he discussed the 9/11 events openly and frankly with his team, sharing with his group the impact of the attack instead of soft-pedalling. He made personal phone calls to all the CEOs in the World Trade Centre who had lost employees, and enriched connectivity and unity by holding a major interdenominational prayer service. Furthermore, he personally talked with families who had lost loved ones, and addressed thousands of families in the armoury and family assistance centres. Thus Giuliani acted authentically, by transcending the ego and putting the common good and welfare of others first (Quinn, 2004). "Like you, I have people in there I know, care about and love; so please, work with us, and we'll work with you" (Giuliani, 2002, p. 16). Giuliani embodied what authentic leadership is, as proposed by Avolio and Luthans (2006) in that he displayed confident, hopeful, optimistic, moral/ethical and resilient behaviour.

Triggering authentic leadership development

The notion of being a connected and authentic leader resonates with the emerging connection-based society where a premium is placed on leadership that embraces spirituality, emotion, context, creativity, empathy and meaning making (Pink, 2005). Traditional leadership development appears to pay much attention to fixing 'bad leadership' (Avolio, 2004). The focus of leadership development is therefore to identify and diagnose the problem areas and possible causes, and ultimately treat the weak areas to create a more effective leader.

On the other hand, in developing authentic leadership, the emphasis is not on the analysis and adoption of prescriptive techniques and practices; it is not about imitating the thinking, principles and behaviour of people who have already been perceived and branded as effective leaders. Authentic leadership is about uniqueness. The reason why the development of authentic leadership is so unique is because one is encouraged to first look, learn and unleash the unique self as an expression of value and authenticity so that his/her behaviours and thinking emanate from within (Quinn, 2004; Wheatley, 1999). This is done only when an individual courageously and consciously chooses to take the responsibility of becoming more purpose-centred, internally directed, other focused, and externally open (Quinn, 2004). Authentic Leadership Development (ALD) also embraces a novel approach in which a new, richer understanding of growth and leadership development is inseparably intertwined, and that being authentic expands into many relational contexts. Moreover, it is for the authentic leader to discover his/her positive psychological capital in the form of confidence, hope, optimism, ethics and resiliency (Avolio \& Luthans, 2006).

Luthans and Avolio (2003) would consider 9/11 a trigger, which they suggest is a prerequisite for growth and ALD. Luthans and Avolio (2003) propose a model for ALD, and central to this model is the trigger event (see Figure 1). They describe a trigger similarly to what Goleman (2002) describes as a "wake up call". These triggers can be sudden, shocking discoveries about one's self that may shake people into action or can be longer in duration. The triggers may be planned or unplanned events that provoke that "A-ha!" moment, where a person confronts a stark truth or realisation and thus gains new insight and perspective about his/her life. At such moments a leader may discover "this is the real me" (George, 2003, p. xvi). Some leaders may ignore the awakening; others may deny it. However, an authentic leader hears the wake-up call and takes the proactive first step in self-directed learning. Luthans and Avolio (2003) primarily focus on the impact a negative trigger has on ALD, however, these authors recognise and explore the concept of planned positive triggers through rigorous design (Avolio \& Luthans, 2006).

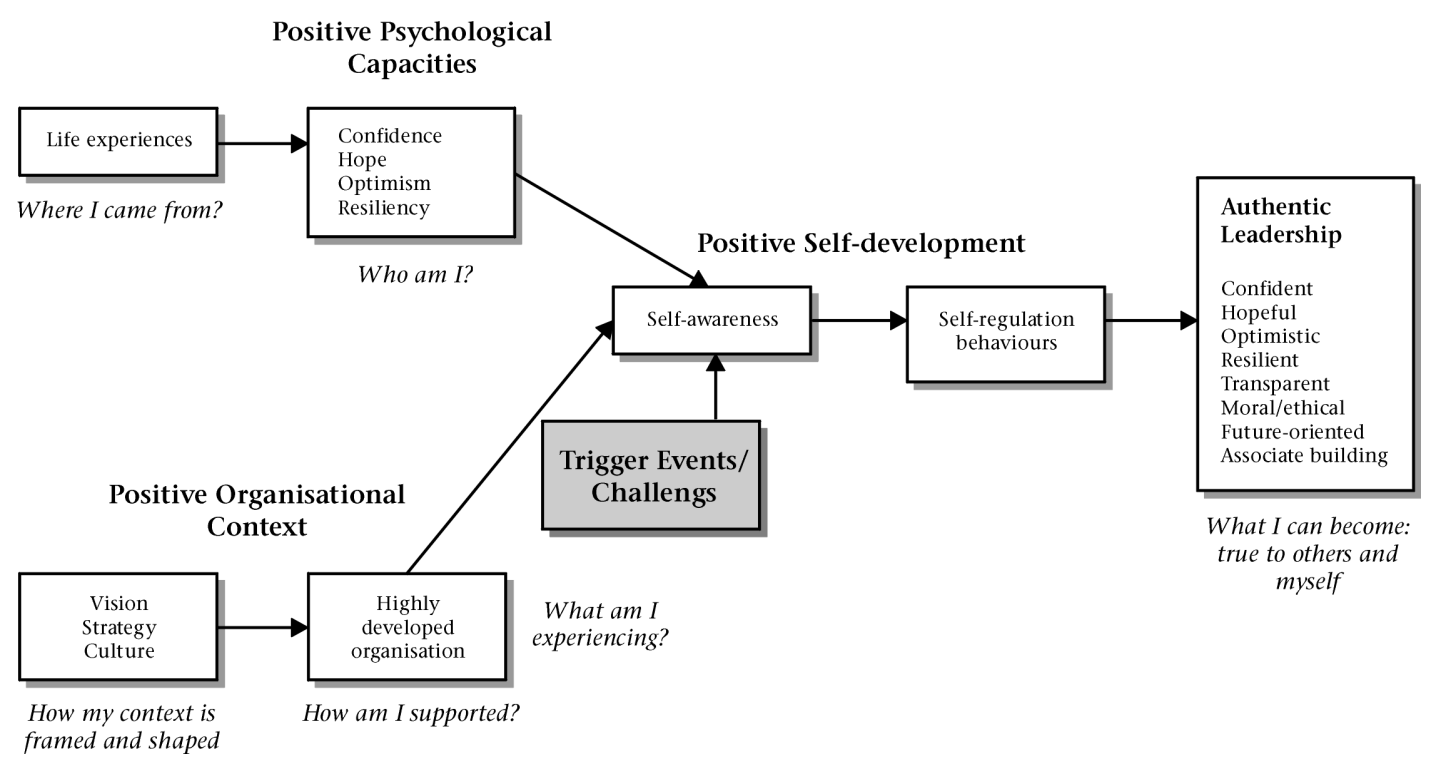

Figure 1: An Authentic Leadership Development Model (Luthans \& Avolio, 2003, p. 251) 
The question therefore is whether a positive trigger event, as opposed to a negative trigger event, can play a fundamental role in developing the authentic leader. Trigger events serve as powerful learning curves. It is questionable whether ALD which is aimed at solving one's leadership deficiencies would necessarily create sustainable authentic leaders. An alternative to deficit-based leadership development is a strength-based approach (Cooperrider, Whitney and Stavros, 2003; Quinn, 2004). A need for an approach that is embedded in the relational and contextual, which is congruent with the zeitgeist of the connection-based economy (Pink, 2005) is required. Appreciative Inquiry (AI) is a positive alternative approach. AI is a relational and connective process, which should encourage conversation, meaning making, and mutual reciprocal relationships (Wheatley, 2002). The power of AI is that it focuses on the possibilities of developing authentic potential and talent, rather than focusing on one's weaknesses and shortcomings, or perhaps something that is not natural to his/her leadership style (Cooperrider et al., 2003) .

\section{Appreciative Inquiry}

AI is a bold shift in the way leadership development is viewed and approached (Schiller, Holland \& Riley, 2002). AI does not aim to change a person's leadership style. The aim of this leadership development approach is to uncover and bring forth existing strengths, hopes and awareness to identify the positive core and inner voice within every leader. In so doing, it transforms the individual, and therefore the organisation, the family, the community. In fact, the ripple effect even impacts on the world as a whole (Wheatley, 1999).

The following four principles have been adapted from AI (Whitney \& Trosten-Bloom, 2003) to form the touchstones of authentic leadership development:

- Authentic leadership development focuses primarily on the whole person:

- Authentic leadership development leverages the power of culture and the potential positive impact it has on an organisation;

- Authentic leadership development takes place within a context that is unique and inimitable; and

- Authentic leadership development is captured through powerful and engaging imagery, visions and positive emotions.

For the purpose of this study, AI was selected as an approach to leadership development because it is both a philosophy (a way of thinking) and a practice (a way of doing) (Van Vuuren \& Crous, 2005). As a way of thinking, it is relational and reflective. As a way of doing, it is a collaborative and participatory exercise grounded in affirmation and appreciation of natural leadership strengths (Whitney \& Trosten-Bloom, 2003). AI is the only validated positive approach to action research.

As a method for affirmative leadership development, AI is collaborative, yet methodical and practical in the way it identifies and leverages strengths. There is no one best way of facilitating an AI, and multiple models have been developed (Magruder \& Mohr, 2001). However, the most dominant model is the AI 4-D Cycle, a systematic and workable process (Van Vuuren \& Crous, 2005). It begins with the selection of an affirmative topic, followed by Discovery (appreciating what is), Dream (imagining what might be), Design (what should be), and Destiny (learning, making the dream real and sustainable).

\section{Affirmative topic choice}

An appreciative topic is always affirmative, desirable and directional, in that it leads the group where they want to go (Cooperrider, Whitney \& Stavros, 2003). Selecting a topic choice is premised by the principle that human systems grow in the direction of their deepest and most frequent inquiries. The $\mathrm{AI}$ process truly begins when a conscious choice is made to focus on affirmative positive leadership development (Cooperrider, Whitney \& Stavros, 2003). Instead of focusing on the severity of leadership deficiencies, AI focuses on peak experiences, best practices and noble accomplishments (Ludema, Cooperrider \& Barrett, 2001).

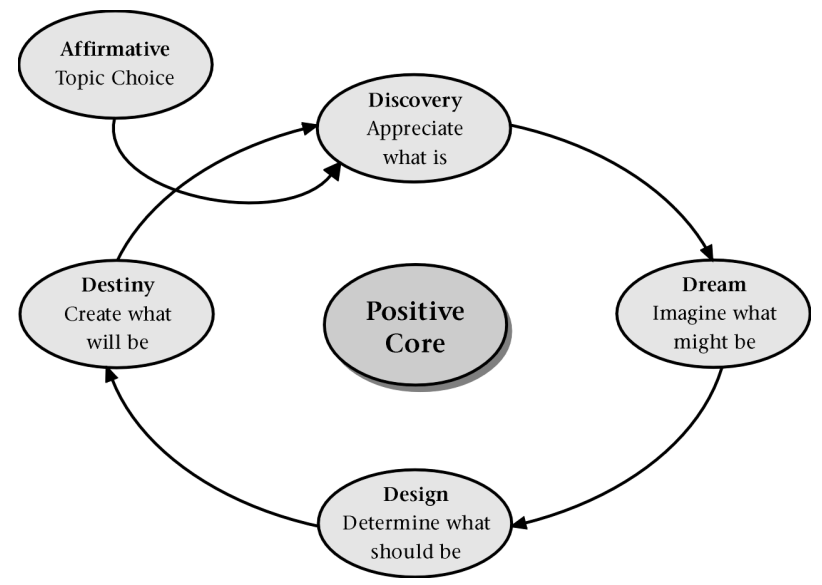

Figure 2: The 4-D Cycle (Cooperrider, Whitney \& Stavros, 2003, p. 5).

\section{Discovery}

The discovery phase is founded on the essential component of the power of conversation. The AI interview is a tool for exploring the life-giving forces at the core of each person's leadership strength (Avital \& Cooperrider, 2004). The interviews are embedded in what is at the heart of AI - the "art of the positive question". The questions asked, and the focal points of conversation determine what the leader will find and develop. These dialogues form the basis of the data that will be used to envision the future. According to Wheatley (2002), real change begins with the simple act of people talking about what they care about, and this gives birth to powerful actions that are able to restore hope to the future.

\section{Dream}

As leadership is given a new voice, a unique conversation and understanding begins to emerge. Because these perspectives have been unearthed from unconditional positive questions, the vocabulary is rooted from a strengthbased story-telling process. Therefore participants are able to envision their reality of authentic leadership in a creative, alternative and positive manner (Ludema, Cooperrider \& Barrett, 2001). By generating words, phrases and stories that mirror the leader at his/her best, coupled with visual drawings of what one could and should become in terms of authentic leadership, the dream phase liberates one from a traditional deficit-based/problem solving paradigm to one of positive imagery and hope.

\section{Design}

The core feature of the design phase is a set of provocative propositions which are built on the notion that words create worlds. They build the bridges between the best of 'what is' and the best of 'what might be'. They are statements that stretch the realm of the status quo, challenge common leadership routines, and suggest tangible actions (Whitney \& Trosten-Bloom, 2003). The provocative proposition is a statement of intention that is grounded in the realties of what was authentic in the past. This phase involves the collective construction of positive images of future authentic leadership in action, based on a chosen social architecture (Cooperrider et al., 2003). The social architecture consists of certain 'design elements', which guide a person to enact his/her future image of an authentic leader. For this study the design elements were, purpose, principles, people and practices (see Table 7). 


\section{Destiny}

The destiny phase asks from each participant a commitment to "sustain the design from the dream that was discovered" (Cooperrider et al., 2003, p. 182). It is a series of inspired actions that support ongoing learning and innovation (Whitney \& Trosten-Bloom, 2003). During this phase leadership commitments are discussed and mobilised, and it's an invitation for deep change. When applying the AI process, the future is consciously constructed upon its positive core strengths - that which gives life and vitality to the leader (Cooperrider et al., 2003).

\section{Aim of the study}

As a result, the AI process is meaningful, engaging, life giving, and it unleashes the positive core and a deep calling within the leader in his/her context. It is a relational, interactive, multidimensional and energising process. The manner in which AI was applied in creating a planned positive trigger event for ALD is subsequently illustrated by means of a descriptive case study (Yin, 2003). The aim of the descriptive case study is to illustrate the process and application of the Appreciative Inquiry method as a positive trigger event in the development of authentic leaders.

\section{RESEARCH DESIGN}

\section{Research approach}

Action research was seen as the most apt methodology for this study because it is a form of inquiry that is collective, collaborative, self-reflective, and undertaken by the participants of the inquiry (Reason \& Bradbury, 2001). For the purpose of this study, the role of the primary researcher was to record and observe to what extent AI could be applied in creating a positive planned trigger event for ALD.

Action research is a participatory, democratic process concerned with developing practical knowing in the pursuit of worthwhile meaning-making, grounded in a participative and connecting worldview which is emerging at this historical time (Reason \& Bradbury, 2001). Considering that authenticity is a positive construct, AI was identified as an appropriate and rigorous procedure for analysis, synthesis and reporting within a qualitative paradigm.

\section{Participants}

As part of an organisational development initiative, managers from an on-line marketing and advertising company based in Cape Town were invited to participate in a one-day AI workshop on authentic leadership development. Participants were informed that the intervention formed part of a research project.

The sample consisted of 22 self-nominated managers (fifteen females and seven males). The average age of the participants was 33. The assumption was that self-nominated managers were more inclined to make a conscious decision to participate, learn, and contribute to the process of the one-day appreciative workshop.

\section{Procedure}

The workshop took place at an independent conference venue off site from the organisation. An experienced, accredited AI practitioner facilitated the AI workshop. The group of 22 were divided into three functional sub-groups of six to eight people each. The participants remained in these groups for the duration of the workshop.

Data collection, analysis and synthesis

For the purpose of data collection, each participant received a workbook. The workbooks contained an appreciative interview guide, as well as space to record the outcomes of each phase within the AI process. No personal particulars were disclosed on the workbooks. This ensured anonymity. For every step of the 4D model, each sub-group would generate and co-construct meaning, and thereafter, share this new meaning with the larger group. All ideas and thoughts were recorded on flip chart paper by the team's appointed scribe, and then transferred to their workbooks. At the end of the workshop, the workbooks and the flip chart papers were collected and coded, and this material formed the basis for data reporting. The ethics of AI is grounded in its constructiveness and positive approach in that it encourages a search for common ground.

In an AI process narrative analyses take place (Watkins \& Mohr, 2001) but also results in a synthesis of meaning making through collaborative dialogue amongst participants. The role of the primary researcher, and the facilitator of the process, was to ensure that the participants followed and gave expression to the AI 4-D process and to ensure that the participants gave content to the construction of positive authentic leadership development.

\section{CASE STUDY REPORTING}

Introducing the workshop, the facilitator sensitised the group to what the essence of Appreciative Inquiry and Authentic Leadership Development is. For the purpose of this intervention, an interview guide was developed as part of the workbook. This interview guide consisted of ten unconditional positive questions adapted from the Encyclopaedia of Positive Questions (Whitney, Cooperrider, Kaplan \& Trosten-Bloom, 2002). This served as the data collection instrument for the discovery phase of this study. (See Table 1).

The workbooks were distributed, and participants were asked to engage in interviews with each other for 45 minutes, according to the interview guide. These interviews sparked energising conversations which were embedded within an affirmative framework of positive questions and sense making.

TABLE 1

THE APPRECIATIVE INTERVIEW GUIDE

\section{Interviews in pairs}

Tell me about a time you worked with someone you considered to be an authentic leader. Describe the situation. What made it authentic for you? What did the leader do that made him/her authentic? Tell me your story.

What did you learn about authentic leadership from this situation?

Warren Bennis writes, "Letting the self emerge is the essential task of leaders". Tell me about a time when you were the source of authentic leadership. What made you authentic? How did you feel at the time? How did others respond? Tell me your story.

Tell me about a time you experienced authentic leadership outside the organisation. What did it look like? How did it inspire you? Describe the situation.

What do you most value and appreciate about leadership at X?

When people are being authentic leaders, what two or three things can they do that will help you to be the best you can be?

What do you think customers admire and value about X? What makes $\mathrm{X}$ unique and cutting edge compared with its competitors?

As you continuously seek to develop into the best leader you can be, can you share with me how you generate your own inspiration to lead authentically? [Mention what personal, spiritual, and developmental practices you have found most useful.]

What is the core factor that 'gives life' to $\mathrm{X}$ ?

What are the three most important hopes you have to heighten the health and vitality of $\mathrm{X}$ for the future? 
From these conversations, 31 appreciative, life-giving leadershiprelated themes were identified (see Table 2). Each sub-group shared their themes with the greater group (plenary feedback). These themes were written on the flip charts and then hung up on the walls of the training venue. All the participants had an opportunity to vote, and proceeded to assign stickers to the themes they felt were most compelling and relevant to authentic leadership.

TABLE 2

SCATTERGRAM CHART

\begin{tabular}{lc}
\hline Life-giving themes & $\begin{array}{c}\text { Number of } \\
\text { stickers }\end{array}$ \\
\hline Becoming balanced & 21 \\
Integrity & 18 \\
Sum of us is greater than the one of us (servant leadership) & 14 \\
You will never find a good leader at the head of the table & 13 \\
(servant leadership) & \\
Learning culture & 11 \\
People, not employees & 11 \\
Empowering & 10 \\
Fun & 9 \\
Communication as the foundation of growth & 8 \\
Knowledge sharing & 8 \\
Being goal focused & 7 \\
'Feel good' - proud & 7 \\
Genuine collaboration & 6 \\
Earning respect & 5 \\
The impact of positive actions & 5 \\
Leaders allow you to succeed or fail & 5 \\
Teamwork/collaboration & 5 \\
Building towards vision & 5 \\
Recognising different approaches to achieving common goals & 4 \\
Adversity contains learning and opportunity & 4 \\
Honesty and open communication & 4 \\
Leaders lead without leading & 3 \\
Leaders create "mini me's" & 3 \\
Adapting leadership to accommodate different needs & 3 \\
Doing 100 things 1\% better & 2 \\
Leaders encourage ownership of vision & 1 \\
Leaders are infectious & 1 \\
Being assertive not aggressive & 1 \\
Learning from others & 0 \\
Unsuspecting leader & 0 \\
Personalised service & 0 \\
\hline & 0 \\
\hline
\end{tabular}

At the end of the discovery phase the participants prioritised six themes as crucial constructs to take into their future as authentic leaders (dream). These were: balance; integrity; the sum of us is greater than the parts; servant leadership; learning culture; people not employees. (See Table 3 derived from Table 2.). The outcomes of the discovery phase are deemed valid due to the emphasis on dialogue, participation and the democratic nature of the AI process.

For the dream phase, participants imagined how they would like authentic leadership to emerge within the organisation by 2010 . Each group captured their dreams with words that expressed their vision of the characteristics of an authentic leader (see Table 4).

Images have a strong emotional appeal to intuitive knowledge and logical thoughts (De Liefde, 2005), and therefore concluding the dream phase the participants were challenged to become artists by generating a metaphor in visual form which resonated with their vision of an authentic leader. The metaphors and their meanings are presented in Table 5 .
TABLE 3

\section{FUTURE RELATED THEMES}

\begin{tabular}{ll}
\hline Theme title & Supporting statement \\
\hline $\begin{array}{l}\text { Theme one: Leading } \\
\text { with balance }\end{array}$ & $\begin{array}{l}\text { "If you are depleted personally you can't give } \\
\text { professionally" (FC /GP3/02)"Authentic leaders are } \\
\text { self aware, so that they know when their energy is } \\
\text { becoming toxic due to their own personal imbalance" } \\
\text { (Plenary feedback, group 2). }\end{array}$
\end{tabular}

Theme two: Integrity "For me, an authentic leader is driven with heart and purpose, and not ego, status or other insecurities" (Plenary feedback, group). "I enjoy working with person $\mathrm{G}$ because she is not intimated by my expertise. In fact, she encourages me to share my knowledge with her. Although she is my manager, she is not dependent on her position...she doesn't let her title define her as a person" (WB/04 ).

Theme three: The "The sum of us is greater than the part of us" (FC/GP sum is greater than 2/01). "We are all in this together. There is no use in the parts making unilateral decisions, because we all sweat our time and energy in this place. This organisation has so much potential, and I want to be a part of it" (WB/18). "I like to think of my team as the strings of a violin. We all have our own unique role to play, but if we don't work as a team, it's going to sound and look terrible. However, taking that into consideration, if we do sound terrible, we need to get honest feedback from those around us, so that we can improve our melody. This openness should build character to our culture" (Researcher notes, p. 4).

Theme four: Servant "You will never find a good leader at the head of the leadership Table" (FC/GP 1/02)

Theme five: Learning "Person $\mathrm{H}$ makes me feel safe. I can make a blunder, culture but I learn from this mistake, and I'm encouraged to continue being creative and taking a risk" (WB/09). "I used to have a manger who valued his own self development, as well as the development of others. He encouraged our team to share knowledge, and to test, try, fail and learn again"(Plenary feedback, group 1).

Theme six: Employees "I love my work, and I am unique. I have talent, fears, as individual beings hopes and dreams, and I just want to be recognised for that. I think everyone does" (Researcher notes, $\mathrm{p}$. 4). "For me, communication is not left for meetings and e-mails. Communication has to be interpersonal, face to face and spontaneous" (WB/19).

TABLE 4

AUTHENTIC LEADERSHIP QUALITIES

\begin{tabular}{l} 
Theme title \\
\hline Customer and \\
community \\
centred (Ethics) \\
Trusting
\end{tabular}

Positive and optimistic view of others

Supporting statement

"Authentic leaders are genuinely concerned and proactive for the welfare of their customers and the community at large" (Plenary discussion, group 2). "In 2010, organisation X will see us as trustees and not employees" (FC/GP2/04)

"Authentic leaders delegate responsibility on the premise of trust, genuine belief in others, a willingness to develop and empower others and the desire to encourage creative freedom and innovation" (Plenary discussion, group 1 ). He/she creates a space that is safe, challenging and open. "This space is created with the heart and with a genuine desire to share knowledge and develop others and the self" (Plenary discussion, group 1).

Transparency and "We feel an authentic leader encourages inclusiveness communication that results in mutual understanding, skills transfer, growth and a common collective awareness of the team's authentic core" (Plenary discussion, group 1).

Engaging and "It's about actively engaging and connecting with respectful people" (FC/GP3/04 \& 05). "Respect is getting to know others the way they really are, and to learn to understand what drives them, and in this way, motivate and inspire them (Plenary discussion, group 2).

Nurturing vitality "The authentic leader is a balanced, centred person." and energy (FC/GP3/04) "By harnessing a balanced life, we see ourselves nurturing healthy relationships, high energy levels, fuelled passion and physical vitality" (FC/GP2/04 \& 05). 
TABLE 5

VISUAL METAPHORS IN THE DREAM PHASE

\begin{tabular}{ll}
\hline Metaphor & Meaning \\
\hline $\begin{array}{l}\text { Kaleidoscope, Rubik's } \\
\text { cube, Play dough, an } \\
\text { Escher sketch }\end{array}$ & $\begin{array}{l}\text { Abundant energy; ability to focus deeply; } \\
\text { optimism; fulfilling intimate relationships; } \\
\text { creativity and innovation; vitality and } \\
\text { enthusiasm; meaningful performance; } \\
\text { resilience; uniqueness; play and fun; } \\
\text { managing the entire dynamic; holistic; } \\
\text { fluidity (FC/GP2/07 \& 08) }\end{array}$ \\
& $\begin{array}{l}\text { Fun; sense of community; safe to fall; } \\
\text { familiar; creative play (FC/GP3/06). }\end{array}$ \\
Playground & $\begin{array}{l}\text { Refined and polished; energising; multi- } \\
\text { faceted; desirable; cutting edge; timeless; } \\
\text { resilient; grounded (FC/GP1/07). }\end{array}$ \\
\hline
\end{tabular}

From appreciating 'the best of what is' (discovery), to 'imagining bold possibilities' (dream), to exploring 'what should be', the design phase encouraged the participants in crafting their own provocative proposition as a collective and authentic expression of what they as leaders, and as an organisation, should become. Each of the following propositions was collectively crafted within the three groups, and inspired and guided by the discovery and dream phase.

\section{TABle 6}

\section{Provocative propositions}

\begin{tabular}{ll}
\hline Group & Statement \\
\hline Group One & $\begin{array}{l}\text { "We embrace freedom to discover potential and we } \\
\text { contribute positively in every interaction. We are } \\
\text { cohesive" (FC/GP1/04). }\end{array}$ \\
"We keep our fingers on the pulse and our feet on the \\
ground Two grow towards being best of breed in \\
entertainment." (FC/GP2/04).I am energy giving. I \\
talk with you. I accept your feedback and facilitate \\
growth. I make a positive contribution to every \\
interaction and I give you freedom to discover your \\
potential" (FC/GP2/04). \\
"We walk the talk. We let our passions create \\
performance. We are free to play and energise those \\
around us. We see self belief as the highest business \\
achievement" (FC/GP3/04).
\end{tabular}

During the design phase, as reflected in Table 7 , the participants considered their organisation's social architecture by focusing on four elements that facilitate the creation of sustainable alliance: purpose; principles; people and practices (Hock, 1999). This social architecture gave the participants space to enact their dream in an optimal, tangible manner as authentic leaders.

In the final phase of the 4-D Cycle, i.e. destiny, participants were invited to generate ideas for action, and make the future real. Plans and actions were divided into organisational and personal commitments. As a collective endeavour towards authentic leadership, the group decided on the steps of action reflected in Table 8.

At the end of the workshop, and in the positive spirit of AI, participants were asked to complete a valuation of the workshop (as opposed to an evaluation of the day). The participants were asked to what extent they valued the AI process. The feedback was captured in the form of an individual reflective exercise. The participants recorded their valuations in the workbooks, and then returned the workbooks to the researchers. Eighteen of the participants were prepared to share their positive experiences of the day. These are presented in Table 9.
TABLE 7

A SOCIAL ARCHITECTURE FOR AUTHENTIC LEADERSHIP

\begin{tabular}{|c|c|c|c|}
\hline Elements & Group 1 & Group 2 & Group 3 \\
\hline Purpose & $\begin{array}{l}\text { Provide direction } \\
\text { and guidance to } \\
\text { harness collective } \\
\text { strengths } \\
\text { - To achieve the } \\
\text { desired and } \\
\text { necessary goals } \\
\text { enthusiastically }\end{array}$ & $\begin{array}{l}\text { - To set team goals } \\
\text { and align them } \\
\text { with company } \\
\text { goals } \\
\text { - To instil pride in } \\
\text { the company and } \\
\text { the work we do } \\
\text { - To create magic } \\
\text { moments and a } \\
\text { safe space } \\
\text { - To develop and } \\
\text { inspire } \\
\text { - To embrace } \\
\text { diversity }\end{array}$ & $\begin{array}{l}\text { - To harness } \\
\text { individual } \\
\text { potential and } \\
\text { empower } \\
\text { - To shape a } \\
\text { climate for high } \\
\text { performance }\end{array}$ \\
\hline Principles & $\begin{array}{l}\text { - To be genuine, } \\
\text { honest and to } \\
\text { have integrity } \\
\text { - To trust and } \\
\text { support }\end{array}$ & $\begin{array}{l}\text { Trust, respect, } \\
\text { integrity, } \\
\text { empathy, honesty, } \\
\text { collaboration, } \\
\text { lead by example, } \\
\text { bravery, } \\
\text { openness, } \\
\text { fairness }\end{array}$ & $\begin{array}{l}\text { Respect, integrity, } \\
\text { individualising our } \\
\text { clients, focus on } \\
\text { our positives, } \\
\text { value continuous } \\
\text { improvement }\end{array}$ \\
\hline People & $\begin{array}{l}\text { - Listen, fairness, } \\
\text { respect, open } \\
\text { minded, empathy, } \\
\text { consistent, } \\
\text { transparent, and } \\
\text { approachable }\end{array}$ & $\begin{array}{l}\text { We are } \\
\text { collaborative, } \\
\text { sensitive to } \\
\text { individuality, } \\
\text { approachable, } \\
\text { encouraging, } \\
\text { validating, direct, } \\
\text { and open-minded }\end{array}$ & $\begin{array}{l}\text { - Having genuine } \\
\text { interest in } \\
\text { developing people } \\
\text { - Listening to } \\
\text { motivating and } \\
\text { inspiring ideas } \\
\text { - Adopting an } \\
\text { organic (as } \\
\text { opposed to a } \\
\text { mechanistic) way } \\
\text { of thinking }\end{array}$ \\
\hline Practices & $\begin{array}{l}\text { - To communicate } \\
\text { - To be } \\
\text { collaborative and } \\
\text { innovative in all } \\
\text { things we do } \\
\text { - To celebrate } \\
\text { success and reflect } \\
\text { on learning } \\
\text { - To coach and } \\
\text { mentor } \\
\text { - To give and receive } \\
\text { feedback } \\
\text { - To ensure all } \\
\text { teams have tools } \\
\text { and skills to } \\
\text { achieve success } \\
\text { - To lead by example }\end{array}$ & $\begin{array}{l}\text { - Take decisions } \\
\text { collaboratively } \\
\text { - Share leadership } \\
\text { - Stimulate free } \\
\text { thinking } \\
\text { - Implement full } \\
\text { circle feedback } \\
\text { - Manage } \\
\text { outcomes, not } \\
\text { processes } \\
\text { - Reward } \\
\text { innovative } \\
\text { behaviour } \\
\text { - Share learning } \\
\end{array}$ & $\begin{array}{l}\text { - Aligning } \\
\text { communication at } \\
\text { all levels } \\
\text { - Becoming more } \\
\text { accessible as a } \\
\text { team } \\
\text { - Living the energy } \\
\text { and trust we want } \\
\text { to see } \\
\text { - People are trained, } \\
\text { empowered, } \\
\text { supported and } \\
\text { confident }\end{array}$ \\
\hline
\end{tabular}

TABLE 8

AUTHENTIC LEADERSHIP DESTINY

Organisational plans and actions

Enact a culture that emulates knowledge sharing, dispels fear and encourages boldness and innovation. To celebrate success and create a safe space for mistakes. To internalise positive speak by becoming more aware of language, and sharing a contagious positive language to fellow colleagues. "In team meetings, we would like to have a standing item called 'appreciation circle' where people can express their thanks to others" (WB/07/15).

Create structures that support flexi hours, and create new teams where people's core strengths are unleashed (WB/03/15).

Inspire a vision that is sourced from the collective dreams and aspirations (WB/05/15)

Facilitate growth by incorporating authentic leadership and Appreciative Inquiry as alternative sources of training and development programmes with current and potential leaders (WB/09/15).

Pursue and apply people's strengths and talents in their work (WB/11/15

\section{Personal plans and actions}

Master interpersonal skills by engaging in open and honest communication, listening genuinely and making time for other colleagues. It also embraces being more empathic and "having more faith in people", as well as being approachable and able to delegate responsibility (WB/12/15). 
TABLE 9

\section{Valuations}

"I resonated with being appreciative for a change" (WB/04).

"I felt the birth of a paradigm shift today" (WB/18).

"I learnt that positive thinking leads to positive actions" (WB/05).

"I valued the opportunity to share with others and to be heard" (WB/05).

"I think we creatively rediscovered a possible new version of what we can become within the AI approach" (WB/12).

"I thought AI was quite dynamic, as it was tailored to meet the company's special needs and unique contexts" (WB/11).

"Through the dialogue and interviews, one is able to determine what is real and valuable. Through these conversations, relationships are built, rationality is created, goals become important and one feels valuable" (WB/17).

"I enjoyed the day, but the challenge is now implementing our actions and plans" (WB/22).

"I would like to meet again in about three month's time, and re-assess where we are" (WB/01).

"Being an authentic leader is about listening to your positive core" (WB/09). "A very different approach, but really enjoyed it and learnt from it" (WB/15).

"I value the views and input shared amongst my colleagues and that I had the opportunity to share mine and be heard" (WB/20).

"I am not alone in my struggle" (WB/20).

"Think positive and talk positive" (WB/16)

"Who I am reflects on what I do and how I do it" (WB/06).

"Enjoyable and energising" (WB/07).

"Was a very positive look at how we can use our individualism to drive an authentic style of leadership" (WB/13).

"Different outlook. Fresh. Thought provoking" (WB/10).

"A lovely look at balance - spirituality, mental, emotional, physical, career" (WB/12).

\section{DISCUSSION}

In the connection-based economy (Pink, 2005), it is no longer viable or appropriate to label people within a specific style or category of leadership. Authentic leadership cannot be a shorthand identifier. Rather, authentic leadership is the underlying need for self expression, which, when it is excavated to its positive nucleus, is capable of being other focused, internally directed, purpose driven and externally open (Quinn, 2004). The participants engaged in this exercise of unleashing the positive core by means of appreciative interviews. These themes echo what Quinn (2004) identified as the dimensions of authentic leadership.

The participants became other focused (discovery phase transcending the ego; putting the common good and welfare of others first); externally open (dream phase - participants imagine an authentic leader who seeks real feedback and who has vision), internally directed (narrowing the gap between values and behaviours in addition to being confident, hopeful, optimistic and resilient - refer to Figure 1: ALD model) and purpose centred (design phase - an ongoing commitment to create value, energise and convert values into consistent actions).

The group perceived authentic leadership as a co-evolution of changing together towards the same dream and goals, yet maintaining their own uniqueness (similar to the image of the kaleidoscope, where they are able to retain the shape, but are also able to change). According to the workshop group discussions, from the Discovery phase all the way to its Destiny phase, a recurring theme of authentic leadership and life at work in the words of Wheatley (2002) becomes stronger and more capable through systems of collaboration and partnering, not through competition and power struggles.
Apart from the positive psychological capacities like confidence, hope, optimism and resiliency, the data especially support associate building as is evident in Tables 4 and 7 .

The conversations and stories shared during the workshop indicate that being authentic is about being the leader one is created to be, which involves an individual responsibility to be true to one's own unique originality. In articulating and discovering this uniqueness, a leader is able to define herself and realize her natural potential that is properly her own. The authentic self exists within every leader, even if it is unacknowledged and incomplete. The workshop enabled the participants to explore the best of what is (Discovery phase). Hence, the workshop was used as a form of development, helping the participant build a more complete sense of his/her authentic self through personal and collective exploration. Furthermore, the workshop also disclosed that being an authentic leader is a personal virtue (discovering the substantial self with attributes distinctly one's own) as well as a social virtue, (authenticity thrives in context, where individual talents and strengths are respected, valued and acknowledged).

This study has shown that leaders can be sensitised to leadership development by appreciating the best in themselves and in others. Furthermore, it explored how a strength-based trigger was useful in discovering their authentic selves, thereby eliminating the need to emulate others. The group felt that although this was an effective trigger event, sustainability would depend on a combination of coaching, planned and unplanned triggers, a supportive and developed culture, and a personal commitment to unleash the authentic self. These, they felt, were some elements for an effective revelation.

\section{CONCLUSION}

Based on the stories and valuations of this workshop, the managers of the workshop group recognised that authentic leadership is initiated by human relatedness. Furthermore, relationships and performance levels thrive when there is an appreciative eye, when people see the best in one another, and when they share their dreams and ultimate concerns in affirming ways (Cooperrider \& Whitney, 2003). This resonates with the idea of Ubuntu which is based on the idea of "I am because we are", in contrast to Descartes' view of "I think, therefore I am" (De Liefde, 2005, p. 52).

Although the focus of $\mathrm{AI}$ is to value and appreciate the best of what is, there were nevertheless challenges and limitations inherent to the study. One of the factors that disrupted the fluidity of the research was the element of distance. While the participants were based in Cape Town, the researchers were based in Johannesburg which complicated the data verification process. In order to overcome any existing doubt or inconsistency, one of the researchers would follow up on discrepancies by telephonic discussions with the relevant participant(s). The nature of the working environment at the case organisation was a second challenge. Although every effort was made to conduct the workshop off-site at a tranquil location, the workshop was continuously disrupted with phone-calls and participants leaving the room to take business related queries. This disrupted the flow of the AI workshop.

In order for ALD to reach its full potential, a trigger event should be perceived and understood as a fundamental way of living, and therefore, veritable sustainability is a question of integrating a myriad of follow up interventions, such as one-onone interviews, coaching and/or similar AI workshops. This is in line with Avolio and Luthans's (2006) view of an authentic leadership development journey.

This study pitched an unplanned negative trigger event (as in the case of Giuliani) against a positive planned trigger event (as 
seen in the workshop). Both triggers unleash a leader's positive core to authenticity; however, the benefits of capitalizing on planned positive "moments that matter" can be used as a positive leverage in developing authentic leaders. Furthermore, the Appreciative Inquiry intervention created an opportunity for self-definition through dialogue (Taylor, 1991). Despite the variance and nature of the triggers, a recurring theme of being "other focused" emerged in both cases. This demonstrated that when the ideal of authenticity is understood, being authentic is not just a matter of concentrating on one's self, but involves deliberation about how one's commitments make a contribution to the good of the public world in which one is a participant (Guignon, 2004).

It is recommended that future research longitudinally investigates to effect of Appreciative Inquiry on authentic leadership development.

\section{REFERENCES}

Avery, G. (2004). Understanding leadership. London: Sage Publications.

Avital, M., \& Cooperrider, D.L. (2004). Introduction: Advances in appreciative inquiry - constructive discourse and human organisation. In: M. Avital \& D.L. Cooperrider. Advances in appreciative inquiry. (Vol I) Constructive discourse in human organisation. Oxford: Elsevier.

Avolio, B.J. (1999). Full leadership development: Building the vital forces in organisations. London: Sage Publications.

Avolio, B. (2004). 1st Poll Shows Many 'Authentic' Leaders Despite Popular Myth. Retrieved October 14, 2005, from the World Wide Web: http://gli.unl.edu.

Avolio, B.J. \& Luthans, F. (2006). The high impact leader: moments matter in accelerating authentic leadership development. New York: McGraw-Hill.

Bennis, W. G. (1993). An Invented Life: Reflections on leadership and change. New York: Basic Books.

Cooperrider, D. L. \& Whitney, D. (2003). Social Construction: Appreciative inquiry. London: Sage Publications.

Cooperrider, D. L., Whitney, D. \& Stavros, J.M. (2003). Appreciative inquiry handbook. Bedford Heights: Lakeshore.

Covey, S.R. (2005). The $8^{\text {th }}$ habit: From effectiveness to greatness. London: Simon and Schuster.

De Liefde, W.H.L. (2005). Lekgotla: The art of leadership through dialogue. South Africa: Jacana Media.

George, B. (2003). Authentic leadership: Rediscovering the secrets to creating lasting value. San Fransisco: Jossey Bass.

Giuliani, R. (2002). Leadership. London: Time Warner.

Goleman, D. (2002). The new leaders: Transforming the art of leadership into the science of results. London: Time Warner.

Guignon, C. (2004). On being authentic. New York: Routledge.

Hock, D. (1999). The Chaordic Organization. San Francisco: Berrett-Koehler.

Kerik, B., Mindel, S. \& Von Essen, T. (2001). Rudolph Giuliani: person of the year. Time Magazine, 158 (28), 26-36.
Lewin, R. \& Regine, B. (1999). The soul at work. London: Orion Publishing.

Ludema, J.D., Cooperrider, D.L. \& Barrett, F.J. (2001). Appreciative inquiry: the power of the unconditional positive question. In P. Reason \& H. Bradbury (Eds.), Handbook of action research: Participative inquiry and practice. London: Sage Publications.

Luthans, F., \& Avolio, B. (2003). Authentic leadership development. In Cameron, K.S., Dutton, J.E. and Quinn, R.E. (Eds), Positive Organisational Scholarship: Foundations of a new discipline. San Fransisco: Berret-Koehler.

Magruder, W.J. \& Mohr, B.J. (2001). Appreciative Inquiry: Change at the speed of imagination. San Fransisco: Jossey-Bass.

McCauley, C.D., Moxley, R.S. \& Van Velsor, E. (1998). The center for creative leadership: Handbook of leadership development. San Fransisco: Jossey Bass.

Nelson, L. \& Quick, J.C. (2004). Organisational behavior. Canada: Thomson.

Payne, R.L. (1996). Contextualism in context. In Cooper, C.L. \& Robertson, I.T. (Eds). International review of industrial and organizational psychology. New York: John Wiley.

Pink, D. (2005). A whole new mind. New York: Riverhead books.

Quinn, R.E. (1998). Deep change: discovering the leader within. California: Jossey-Bass.

Quinn, R.E. (2004). Building the bridge as you walk on it: a guide for leading change. San Francisco: Jossey Bass.

Reason, P. \& Bradbury, H. (2001). Handbook of action research: participative inquiry and practice. London: Sage Publishers.

Schiller, M., Holland, B.M. \& Riley, D., (2002). Appreciative Leaders: In the eye of the beholder. A Taos Institute Publication.

Sharma, R.S. (1998). Leadership wisdom from the monk who sold his Ferrari: The eight rituals for visionary leaders. Canada: Harper Collins.

Shipka, B. (1997). Leadership in a challenging world: A sacred journey. Oxford: Butterworth-Heinemann.

Taylor, C. (1991). The ethics of authenticity. Cambridge: Harvard University Press.

Van Vuuren, L.J. \& Crous, F. (2005). Utilising appreciative inquiry (AI) in creating shared meaning of ethics in organizations. Journal of Business Ethics, 57, 300-412.

Watkins, J.M. \& Mohr, B.J. (2001). Appreciative inquiry: Change at the speed of imagination. San Francisco: Jossey Bass/Pheiffer.

Wheatley, M.J. (1999). Leadership and the new science: Discovering order in a chaotic world. San Fransisco: Berret-Koehler.

Wheatley, M.J. (2002). Turning to one another: simple conversations to restore hope to the future. San Fransisco: Berret-Koehler.

Whitney, D. \& Trosten-Bloom, A. (2003). The power of appreciative inquiry. San Fransisco: Berrett-Koehler.

Whitney, D., Cooperrider, D., Trosten-Bloom, A. \& Kaplan, B. (2002). Encyclopaedia of positive questions: Vol. (1). Euclid: Lakeshore.

Yin, R.K. (2003). Applications of case study research (2nd ed.). Thousand Oaks: Sage Publishers. 